\title{
EUROPEAN LAND QUALITY AS A FOUNDATION FOR THE SUSTAINABLE INTENSIFICATION OF AGRICULTURE
}

\author{
Winfried E.H. BLUM ${ }^{1 *}$, Jasmin SCHIEFER ${ }^{1}$, Georg J. LAIR ${ }^{1,2}$
}

\begin{abstract}
Based on 3 large European sets of soil and land data 6 land indicators for soil resilience and soil performance were chosen for defining land and soil surfaces in Europe, on which sustainable agricultural production can be achieved and under which conditions. In this context, also desintensification on specific areas was proposed in order to achieve sustainability and environmentally safe conditions. On this basis data for arable land in 25 states of the EU 28 could be established, indicating that on $41 \%$ of the arable land a sustainable intensification is possible, on $4 \%$ extensification is needed, and on the remaining $55 \%$ no intensification is possible or only with restrictions.
\end{abstract}

Keywords: arable land, agricultural intensification, sustainability, soil and land indicators, soil resilience, soil performance, Europe

\section{INTRODUCTION AND DEFINITION OF THE AIMS}

By 2050, the world population will reach more than 9 billion according to actual UN projections (Alexandratos and Bruinsma, 2012). Besides the growth of population, higher per-capita income, and increasing demand for meat/ fish and dairy products, the total demand for food will increase (Godfray et al., 2010). The "green revolution" starting in the 1960s allowed an enormous increase of yield in the past 40 years mainly due to greater inputs of fertilizers, irrigation, new crop strains, agricultural machineries and other technologies (Tilman et al., 2002). However, studies show that the increase of yields at the current state would not meet the future demand for food (Ray et al., 2013). To meet the needs of agricultural products by 2050, further intensification of food production will be necessary. It has to be considered, that high input production needs more energy, fertilizer and irrigation. This has adverse effects on soil and

\footnotetext{
${ }^{1}$ Institute of Soil Research, University of Natural Resources and Life Sciences (BOKU) Vienna, Peter Jordan-Strasse 82a, 1190 Vienna, Austria

${ }^{2}$ Institute of Ecology, University of Innsbruck, Sternwartestrasse 15, 6020 Innsbruck, Austria

*Corresponding author: winfried.blum@boku.ac.at
} 
environmental quality such as biodiversity, groundwater and surface water quality, and air due to greenhouse gas emissions.

An agricultural production, where "yields are increased without adverse environmental impact and without the cultivation of more land", is defined as "Sustainable intensification" SI (The Royal Society London, 2009). This form of production combines energy flows, nutrient cycling, population-regulating mechanisms, and system resilience to intensify existing arable land without harm to the environment or other economic or social factors (Pretty, 2008).

As food security is intimately related to soil security and sustainable agriculture (The Royal Society London, 2009), the resilience (the capacity of systems to return to a (new) equilibrium after disturbance) and performance (the capacity of systems to produce over long periods) of soil under intensification must be considered (see also Blum and Eswaran, 2004).

Soils perform environmental, social, and economic functions (Blum, 2005): (1) biomass production for different uses; (2) buffering, filtering, biochemical transformation; (3) gene reservoir; (4) physical basis for human infrastructure; (5) source of raw materials and (6) geogenic and cultural heritage. Sustainable land use has to harmonize the use of these six soil functions in space and time, minimizing irreversible uses like sealing, excavation, sedimentation, acidification, contamination or pollution, and salinization (Blum, 2005).

To define the capacity of soil systems to provide goods and services for a long term, indicators have been chosen which are comprehensive enough to characterize the intrinsic potential of soils to level out or to reduce negative impacts of agricultural intensification. Fertile soils with specific characteristics have a high resilience against physical, chemical and biological disturbances such as erosion, compaction, contamination of air, plants and water, and against loss of biodiversity. They can therefore protect the groundwater against contamination, maintain biodiversity and reduce or minimize erosion and compaction. Soils with these characteristics also show a high performance and can produce a maximum of agricultural commodities if managed accordingly.

The main objective of this work was to identify the most important soil intrinsic parameters (indicators) which determine soil resilience and performance according to the ecological functions of soil.

\section{MATERIAL AND METHODS}

The suitability for SI is based on intrinsic soil quality parameters such as 'resilience' against adverse ecological impact and 'performance' in the sense of long lasting productivity and was defined with 6 soil parameters (= indicators). The indicators 
presented in Table 1 were chosen based on available literature and expert knowledge. They were scored according to defined threshold levels in terms of poor (1), medium (2), good (3) and in some cases excellent (4) conditions.

\begin{tabular}{lrrccc}
\hline & excellent & good & medium & poor & unit \\
\hline SOC \% & $\geq 4$ & $2-4$ & $1-2$ & $\leq 1$ & $\%$ \\
Clay+Silt & $\geq 50$ & $35-50$ & $15-35$ & $\leq 15$ & $\%$ \\
\hline $\boldsymbol{p H}$ & & $6.5-7.5$ & $5.5-6.5 ; 7.5-8.5$ & $\leq 5.5 ; \geq 8.5$ & in $\mathrm{H}_{2} \mathrm{O}$ \\
CEC & $>25$ & $10-25$ & $\leq 10$ & $\mathrm{cmol} / \mathrm{kg}$ \\
Depth $^{*}$ & & $\geq 60$ & $30-60$ & $\leq 30$ & $\mathrm{~cm}$ \\
Slope $^{* *}$ & & $\leq 8$ & $8-15$ & $15-25$ & $\%$ \\
\hline
\end{tabular}

* Estimated according to WRB 2006 (see Schiefer et al., 2015)

** Sites with slopes $>25 \%$ were excluded from calculations

Data for these indicators have been taken from the Land Use/Land Cover Area Frame Survey 2009 (LUCAS), i.e. soil organic carbon (SOC) content, clay+ silt content, soil $\mathrm{pH}$, and cation exchange capacity (CEC), which was carried out in 25 member states, and the European Soil Data Base (ESDB) 2.0 1:1,000,000 (i.e. slope and depth) provided by IES/JRC European Commission. To exclude sites not under agricultural cropping, a map of arable land from Corine Land Use Cover (CLC 2000) was used. All analysis was carried out with ArcGIS 10.2.

By summing up all the scores, a minimum value of 6 and a maximum value of 20 (4 points for SOC content as well as for clay + silt content and 3 points for $\mathrm{pH}, \mathrm{CEC}$, depth and slope, respectively) could be attributed to a land unit. The total score points were separated into four different categories of SI potential.

Land with lowest quality has only a final score between 6 and 10 (category 1). This means that the soil has intrinsic properties, which cannot support environmentally friendly intensification and therefore even extensification is suggested. Land in category 2 can show medium or good conditions (score $>10$ ), but one or even more indicators are in a "poor" condition (see table 1) and therefore an intensification is only possible with a high risk. A total score of 11 to 15 represents the medium category 3 , where a low potential for SI is given, meaning that intensification should only be done with much caution. Land which can be recommended for SI (category 4) presents soils, which can compensate environmental impacts, show good agricultural production, and have a total score from 16 to 20 . This land was recommended for intensive agriculture under the precondition that it is managed in a sustainable way.

This classification scheme was also applied at a local scale in Rutzendorf/Marchfeld in the eastern part of Austria (Figure 1). Data were taken from the soil quality index for cropping which was elaborated by the Austrian Soil Taxation using a very detailed raster for soil sampling (40-60 meters). 


\section{RESULTS AND DISCUSSION}

This work is a conceptual approach in order to identify soils with a potential for SI based on existing data. Because of a lack of data, not all arable land could be covered by this study. The results show for an analyzed area of $671.672 \mathrm{~km}^{2}$ of arable land in Europe, that almost half of it $(49 \%$; class $1+2)$ is not suitable for sustainable intensification. Out of this, $4 \%$ have such bad intrinsic soil qualities that intensification cannot be considered (class 1). It is recommended to rather de- intensify and to reduce land use intensity in order to avoid environmental harm. $12 \%$ of the area is in medium conditions, which means that a sustainable intensification on this land is not possible at the present state. This land should be used with precaution. Intensification without environmental risks can only be implemented at $41 \%$ of the analyzed land, because this land has a high resilience against negative impacts from intensive agricultural production and showing a high performance at the same time.

The most frequent limiting factor for sustainable intensification is the cation exchange capacity (CEC). Clay content, $\mathrm{pH}$ and soil organic carbon (SOC) cause similar constraints in many areas. These soil properties influence each other and are also linked to the CEC.

Portugal, Poland, Greece and Spain are examples for countries with limited soil resources for intensive agriculture. Soils in regions around river basins in general show positive resilience and persistence. It is also found that proportionally seen, agricultural land suitable for SI counts for more than $60 \%$ in Belgium, Slovak Republic, the United Kingdom, Latvia, the Netherlands and Hungary.

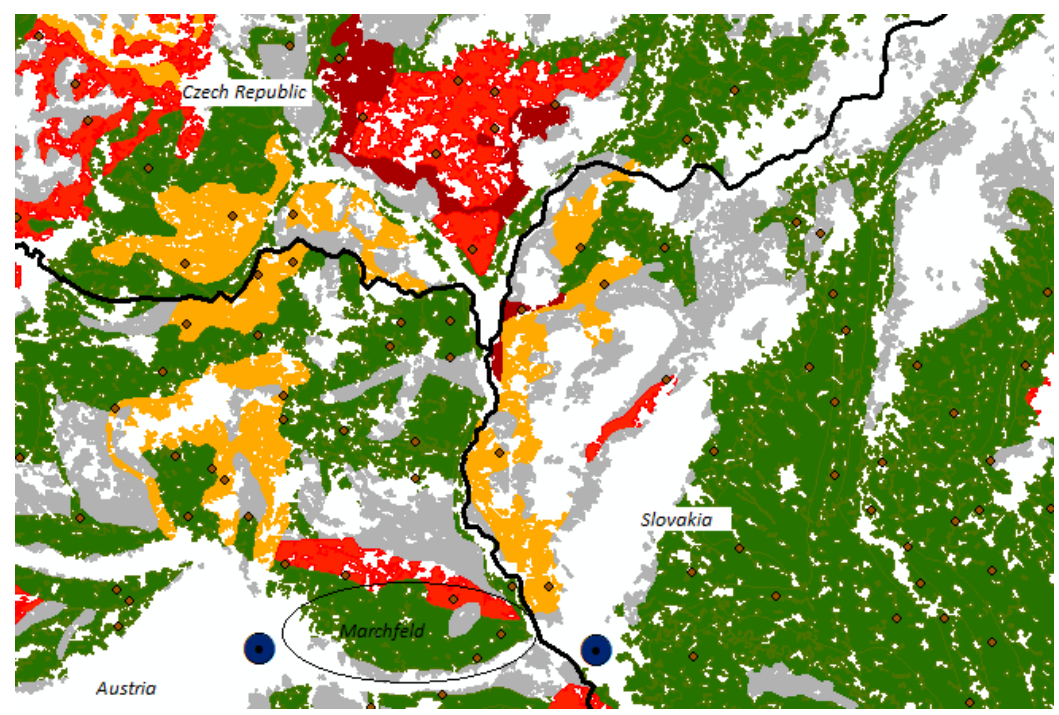

Figure 1. Land suitability for SI in Austria (Marchfeld), Czech Republic and Slovakia 


\section{REFERENCES}

Alexandratos, N. and Bruinsma, J. (2012). World agriculture towards 2030/2050: the 2012 revision. ESA Working paper No. 12-03. Rome, FAO.

Blum, W.E.H. and Eswaran, H. (2004). Soils for Sustaining Global Food Production.

Journal of Food Science 69-2, 37-42.

Blum, W.E.H. (2005). Functions of Soil for Society and the Environment. Reviews in Environmental Science and Bio/Technology 4, 75-79.

Godfray, H.C.J., Beddington, J.R., Crute, I.R., Haddad, L., Lawrence, D., Muir, J.F., Pretty, J., Robinson, S., Thomas, S.M., Toulmin, C. (2010). Food Security: The Challenge of Feeding 9 Billion People. Science $327,812-818$.

Pretty, J. (2008). Agricultural sustainability: concepts, principles and evidence. Philos.

Trans. R. Soc. B Biol. Sci. 363, 447-465.

Ray, D.K., Mueller, N.D., West, P.C., Foley, J.A. (2013). Yield Trends are insufficient to Double Global Crop Production by 2050. PLoS ONE 8, e66428.

RISE(2014). The sustainable intensification of European agriculture, pp. 5762. The RISE Foundation Brussels, www.risefoundation.eu.

The Royal Society (London) (2009). Reaping the benefits science and the sustainable intensification of global agriculture. The Royal Society, London.

Tilman, D., Cassman, K.G., Matson, P.A., Naylor, R., Polasky, S. (2002). Agricultural sustainability and intensive production practices. Nature $418,671-677$. 